\title{
La apropiación del espacio público como lugar de relaciones y vivencias
}

\author{
Laura Luque Rodrigo | Dpto. De Patrimonio Histórico, Universidad de Jaén \\ URL de la contribución <www.iaph.es/revistaph/index.php/revistaph/article/view/4369>
}

En 2030, cerca de 5000 millones de personas (aproximadamente el $60 \%$ de la población mundial) vivirá en ciudades (CIUDADES, 2015). Esta rápida urbanización comporta una serie de perjuicios por lo que uno de los objetivos de la ONU es precisamente mejorar la gestión urbanística para lograr ciudades más sostenibles, resilientes y seguras. Por ello, proponen aumentar las políticas participativas e inclusivas en la planificación urbana (CIUDADES, 2015).

La Nueva Agenda Urbana (HÁBITAT, 2017) y a nivel normativo europeo, la Carta de Leipzig sobre Ciudades Europeas Sostenibles, pretenden regular el desarrollo de la ciudad contemporánea, desde la sostenibilidad, la versatilidad, la eficiencia y la accesibilidad. En España, se materializa a través del Libro Blanco de la Sostenibilidad en el Planeamiento Urbanístico Español que tiene como finalidad servir de guía (FARIÑA TOJO, 2010), a la municipalidad. El Libro Blanco propone un decálogo, en cuyo punto siete destaca la importancia de la participación ciudadana.

Sin embargo, las ciudades siguen presentando graves problemas, por ejemplo, el hecho de que los modelos urbanos estén centrados en el automóvil, lo que determina un uso de la ciudad por parte de los ciudadanos que antepone la circulación a las relaciones.

Otro problema es la falta de espacios públicos, sobre todo espacios verdes. El Fondo de Población de las Naciones Unidas (UNFPA) y ICLEI-Gobiernos locales por la sostenibilidad, así como otros organismos, se están preocupando por los efectos negativos del tráfico rodado a nivel medioambiental y de salud. Sin embargo, se tratan poco los perjuicios sociales a nivel psicológico y de relaciones.
Algunos teóricos sí se han preocupado por "encontrar el momento de instaurar una nueva habitabilidad más creativa, más sincera, a partir de la cual hacer que los espacios colectivos adquieran un nuevo sentido para la vida de sus habitantes" (MORENO PÉREZ; MÁRQUEZ BALLESTEROS, 2011: 40). Jaime Lerner creó el concepto de acupuntura urbana, definido como cualquier actuación que produzca efectos positivos en la ciudad (LERNER, 2010). También los artistas, desde colectivos como Boa Mistura o Basurama, entre otros muchos, se han preocupado por la apropiación de los espacios por parte de sus habitantes.

Pero, ¿se está permitiendo la participación ciudadana real en la gestación de modelos urbanos? Y sobre todo ¿se están promoviendo políticas que permitan a los ciudadanos apropiarse de los espacios de relación? En muchas ocasiones, estos espacios están ligados preci-

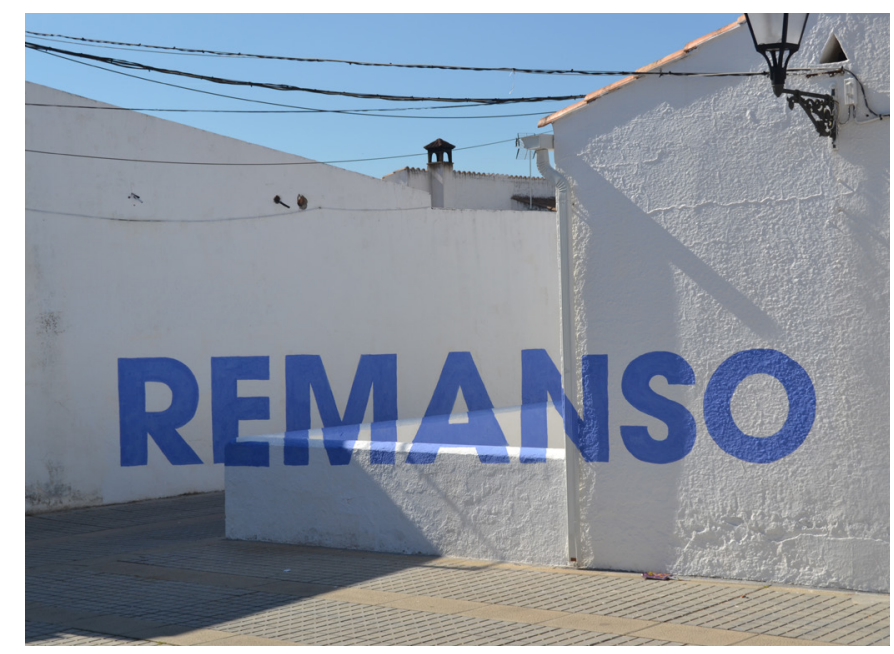

Intervención de Boa Mistura en Maruanas (El Carpio, Córdoba), realizada en 2012 bajo el concepto de acupuntura urbana | foto Laura Luque Rodrigo 
a debate El papel del patrimonio en las nuevas políticas para la cultura, la ciudad y el territorio: las agendas urbanas como marco de oportunidad

| coordinan Blanca del Espino Hidalgo, Rafael Merinero Rodríguez

samente al patrimonio monumental, pero en las ciudades contemporáneas, se limita a las periferias. Además, los centros históricos están sufriendo nuevos problemas que conllevan la pérdida de identidad: la gentrificación (SEQUERA, 2015: 2) y homogeneización de los espacios, que hacen que nuestras ciudades sean menos habitables. ¿Están las agendas urbanas tratando estos problemas? Parece que no. Es cierto que existen iniciativas que promueven la apropiación del espacio por sus gentes, desde asociaciones de vecinos, como Barrio del Oeste en Salamanca o en Palermo, el Comitato Spazio Pubblico, un grupo que comenzó a "invadir" un espacio simbólico de la ciudad, pero ahogado por coches (LOTTA, 2010: 64).

En este sentido podríamos hablar de tendencias ciudadanas, de las que se hacen eco las instituciones, como la de crear huertos urbanos y jardines secretos, desde el Parco Nord de Milán, a cualquier ciudad periférica. Según el diario La Vanguardia "en España hoy existen más de 508 huertos urbanos. Un número que ha crecido desde el año 2000 en un 98\%" (NAVARRO, 2018). Existe también la aparición de jardines secretos, típicos en ciudades como Londres, Roma, Milán o Madrid, espacios semicomunales-semipúblicos, para relación de los vecinos.

En general, las instituciones locales han estado preocupadas por ofrecer nuevas etiquetas a la ciudad contemporánea, con apelativos como "ciudad del conocimiento, smart city, ciudad informacional, ciudad en red, etc." (RODRÍGUEZ BARCÓN; CALO GARCÍA; OTERO ENRÍQUEZ, 2017: 700), promoviendo el acceso a wifi en las calles, entre otras cosas, pero al final suponen una nueva elitización de las urbes que no dan solución a los problemas reales y que desde luego dejan en el olvido a las poblaciones rurales, que se enfrentan a una terrible despoblación.

Por ello, lo primero que debían hacer las agendas urbanas es ser más accesibles, "estar a un click" de los ciudadanos, puesto que si buscamos las agendas urbanas de las capitales andaluzas, apenas encontraremos la de
Málaga, de 2015, que contempla el plan de actuación de 2020 a 2050. Lo interesante es que desde la web permite la participación ciudadana. En relación con el resto de capitales, lo que único que aparece en internet sobre esta cuestión son eventos para la presentación de las agendas españolas y andaluzas. Es decir; constituye una carencia real en nuestra comunidad la participación ciudadana en estas agendas y su correcta difusión. Además, es importante que los equipos tengan un perfil transdisciplinar en los que aparezca el perfil de historiador del arte, junto con arquitectos, urbanistas, sociólogos, antropólogos, etc. Además, sería positiva la participación de artistas, con la idea de crear ciudades heterogéneas e inclusivas, en las que existan nuevas identidades relacionadas con lo contemporáneo y lo creativo, además de lo participativo. Logrado esto, quedan otros campos de batalla, como lograr que las agendas tengan un reflejo normativo real y consensuado, desde las instituciones gubernamentales de carácter global (que aporten directrices generales) a las más locales, pues al final, desde lo particular se podrán construir ciudades resilientes. 
_a debate El papel del patrimonio en las nuevas políticas para la cultura, la ciudad y el territorio: las agendas urbanas como marco de oportunidad

| coordinan Blanca del Espino Hidalgo, Rafael Merinero Rodríguez

\section{BIBLIOGRAFÍA}

- Agenda uRbana de ANDAlucía. Acuerdo de 18 de septiembre de 2018, del Consejo de Gobierno, por el que se aprueba la Agenda Urbana de Andalucía. Boletín Oficial de la Junta de Andalucía, n. ${ }^{\circ}$ 185, lunes 24 de septiembre de $2018<$ <ttps://juntadeandalucia.es/boja/2018/185/BOJA18185-00002-15362-01_00142635.pdf> [Consulta: 08/04/2019] Texto disponible en <http://www.cma.junta-andalucia. es/medioambiente/portal_web/web/temas_ambientales/ urbanismo/agenda_urbana_andalucia_2030.pdf $>$ [Consulta: 08/04/2019]

- AgENDA URBANA ESPAÑOLA [en línea]. Madrid: Gobierno de España, Ministerio de Fomento, 2018 < http://www.aue.gob. es/> [Consulta: 08/04/2019]

- Agenda uRBANA MÁlAgA. Hacia una sociedad sostenible. Málaga: Observatorio de Medio Ambiente Urbano <http://www.omau-malaga.com/17/agenda-urbana> [Consulta: 05/04/2019]

- CIUDADES y comunidades sostenibles. En Objetivos de desarrollo sostenible, 2015 <https://www.un.org/ sustainabledevelopment/es/cities/> [Consulta: 11/06/2018]

- FARIÑA TOJO, J. (dir.) (2010) Libro Blanco de la Sostenibilidad en el Planeamiento Urbanístico Español. Madrid: Ministerio de Vivienda, Centro de Publicaciones, 2010

- hABITAT III: Nueva Agenda Urbana. Conferencia de las Naciones Unidas sobre la Vivienda y el Desarrollo Urbano Sostenible. sl: ONU, 2017 <http://habitat3.org/wp-content/ uploads/NUA-Spanish.pdf> [Consulta: 08/04/2019]

- JORNADA de debate y presentación de la Agenda Urbana Española. sl: Federación Española de Municipios y Provincias, $2018<$ http://femp.femp.es/files/566-2313archivo/Presentacio\%CC\%81n\%20Agenda\%20Urbana.pdf> [Consulta: 08/04/2019]

- LERNER, J. (2010) Acupuntura Urbana. 5. ${ }^{\mathrm{a}}$ ed. sl: Record, 2010

- LOTTA, F. (2010) Reinventar de los espacios públicos en la ciudad contemporánea. En CORNEJO NIETO, C.; MORÁN SÁEZ, J.; PRADA TRIGO, J. (coord.) Ciudad, territorio y paisaje: Reflexiones para un debate multidisciplinar. Madrid: C.E.R.S.A., 2010, pp. 63-67

- MORENO PÉREZ, J. R.; MÁRQUEZ BALLESTEROS, M. J. (2011) La ciudad contemporánea. Uciencia: revista cuatrimestral de divulgación científica, n. ${ }^{\circ} 8$, pp. 38-40 <http:// www.uciencia.uma.es/Revista-Uciencia/Ciudad-una-realidadpor-construir> [Consulta: 08/04/2019]

- NAVARRO, R. (2018) Cinco beneficios reales de tener un huerto urbano. La Vanguardia 07/07/2016, actualizado a 30/05/2018 <https://www.lavanguardia.com/vivo/ ciudad/20160707/403006599958/huerto-urbano-cultivo.html> [Consulta: 08/04/2019]

- RODRÍguez BARCón, A.; CALO GARCíA, E.; OtERO ENRÍQUEZ, R. (2017) Producción cultural y turistificación: la construcción de la ciudad creativa en A Coruña. En Actas Cidades Creativas, Icono 14, pp. 699-710

- SEquerA, J. (2015) A 50 años del nacimiento del concepto 'gentrificación'. La mirada anglosajona. Biblio3W: revista bibliográfica de geografía y ciencias sociales, vol. $\mathrm{XX}, \quad$ n. ${ }^{\circ} 1127<$ <ttp://revistes.ub.edu/index.php/b3w/article/ viewFile/26116/27751> [Consulta: 08/04/2019] 